\title{
Neutrosophic logic for MM signal processing and analysis
}

Multimedia Tools and Applications gratefully acknowledges the editorial work of the scholars listed below on the special issue entitled "Neutrosophic Logic for MM Signal Processing and Analysis" (SI 1133 T).

Of 68 papers submitted to this issue, 24 were eventually accepted after a stringent peer review process.

\section{Corresponding Guest Editor}

Mohamed Abdel-Basset

Zagazig University, Egypt

Email: analyst_mohamed@yahoo.com; mohamed.abdelbasset@fci.zu.edu.eg

\section{Guest Editors}

Florentin Smarandache

University of New Mexico, USA

Email: fsmarandache@gmail.com; smarand@unm.edu

\section{Victor Hugo C. de Albuquerque}

University of Fortaleza (UNIFOR), Brazil

Email: victor.albuquerque@unifor.br; victor120585@yahoo.com.br

Publisher's note Springer Nature remains neutral with regard to jurisdictional claims in published maps and institutional affiliations. 